\title{
Etiopathological aspects of Elaphostrongylus cervi and Varestrongylus sagittatus infections in red deer in Bulgaria
}

\author{
Mariana S. Panayotova-Pencheva, Marin T. Alexandrov \\ Institute of Experimental Morphology, Pathology and Anthropology with Museum, \\ Bulgarian Academy of Sciences, Sofia, Bulgaria
}

Received September 24, 2010

Accepted November 15, 2011

\begin{abstract}
One hundred and ten faecal samples and five lungs of red deer (aged 2 to 8 years) coming from the State Hunting Enterprise Vitinya in Bulgaria (Balkan Mountain) were examined. A larvoscopic examination of the faeces and helminthological necropsies, pathoanatomical and histological examinations of the lungs were performed. The overall prevalence of protostrongylids was $70 \%$ (77/110), and the prevalence of Elaphostrongylus cervi and Varestrongylus sagittatus was $68 \%$ $(75 / 110)$, and $27 \%(30 / 110)$, respectively. In $25 \%(28 / 110)$ of the faecal samples, mixed infection with $V$. sagittatus and $E$. cervi was found. Mixed protostrongylid infections with those two species were detected in lungs of all animals. The macroscopic lesions found in the lungs parasitized by those helminths were classified as follows: gray, dark-red to black stained portions on the lungs surface varying in shape and size; brown-black nodes clearly differentiated from the surrounding tissue; small, hard subserous nodules. The most frequently observed microscopic abnormalities were desquamatous bronchitis, alveolitis associated with accumulations of alveolar macrophages and eosinophilic granulocytes, haemorrhages in the alveoli and the alveolar septa, development of parasitic granulomas in the interstitium as well as a peribronchial, perilobular, disseminated and intralobular hyperplasia of the lymphoid tissue. The macroscopic and microscopic alterations depended on the species of the parasites found in the inflammatory areas. The infections with $E$. cervi were most often associated with the lesions on the lungs surface varying in color, shape and size and with the small, hard subserous nodules, and those with $V$. sagittatus - with the brownblack nodes clearly differentiated from the surrounding tissue.
\end{abstract}

Cervus elaphus, protostrongylids, lung pathomorphology, lung histology

Infections with protostrongylids (Nematoda: Metastrongyloidea) are rather common in red deer (Cervus elaphus L.). Depending on the parasite species, the pathological changes are of different localization. Elaphostrongylus cervi causes damage to the lungs, the central nervous system and the skeletal musculature, while Varestrongylus sagittatus affects only the lungs. Regardless of the localization, the pathogenic action of these parasites on the host is powerful. The parasitized deer are in a visibly poor health condition, have impaired trophy qualities and useless meat upon shooting. That is why etiological, epidemiological, clinical and pathomorphological investigations on these infections have been carried out in many countries, such as Austria, New Zealand, Scotland, Poland, Denmark, the Czech Republic, Switzerland, Spain, Germany and Italy (Kutzer and Prosl 1975; Sutherland 1976; English et al. 1985; Demiaszkiewicz 1987; Eriksen et al. 1989; Řezáč and Blažek 1991; Pusterla et al. 1998; Vicente and Gortazar 2001; Rehbein et al. 2002; Bregoli et al. 2006). However, these studies are sometimes limited and contradictory. The aim of this study was to perform etiopathological investigations on red deer with natural protostrongylid infections.

\section{Materials and Methods}

The study was carried out from 2005 to 2008 on the territory of the State Hunting Enterprise Vitinya (Balkan Mountain) in Bulgaria. Larval diagnostics by the routine Baermann technique on 110 faecal samples from red

Address for correspondence:

Mariana S. Panayotova-Pencheva

Institute of Experimental Morphology, Pathology and Anthropology with Museum

Bulgarian Academy of Sciences, Acad. G. Bonchev St., Block 25

1113 Sofia, Bulgaria
Phone: $+3592 / 9792334$

Fax: $+3592 / 8710107$

E-mail: marianasp@abv.bo

http://www.vfu.cz/acta-vet/actavet.htm 
deer inhabiting the enterprise was performed. Lungs of five male red deer (three of them were 2 years old, one 6 years old and one 8 years old) shot on the territory of the enterprise were investigated, too. All procedures complied with the requirements of Ordinance No 22/14.12.2005 on reducing the suffering of animals to a minimum at the time of slaughter or killing (Promulgated in SG 22 of 14 Dec 2005 and transposing Directive 93/119/EC on the protection of animals at the time of slaughter or killing) and European Union's Guidelines for the Accommodation and Care of Animals Used for Experimental and Other Scientific Purposes (2007/526/EC). Firstly, routine necropsies of the lungs were performed. After that, the helminths within the particular lesion were determined under the microscope. Abnormal lung tissue was examined after boiling in lactic acid (PanayotovaPencheva and Alexandrov 2010) to find hardly visible small worms located in the bronchioles and alveoli. The identification of the helminths was carried out on the basis of their morphometric characteristics. Small organ pieces $(0.5 \times 2 \times 2 \mathrm{~cm})$ were obtained from the helminthologicaly analyzed (but not boiled) tissue lesions and processed for standard histopathological examination.

\section{Results}

Investigation of the faecal samples of red deer showed that the overall prevalence of protostrongylids was 70\% (77/110), and the prevalence of Elaphostrongylus cervi and Varestrongylus sagittatus was $68 \%(75 / 110)$, and 27\% (30/110), respectively. In $25 \%$ $(28 / 110)$ of the faecal samples, mixed infection with V. sagittatus and E. cervi was found. Mixed protostrongylid infections with those two species were detected in all the necropsied lungs.

Macroscopically visible pathological lesions in the lungs were situated mainly on the dorsal surface of the diaphragm portions. The ventral and mediastinal surfaces were affected to a lower extent. Depending on the characteristics of the macroscopic lesions they were classified into three types: Type 1 - areas scattered on the lung surface varying in shape and size of a gray, dark-red to black coloration, in most cases, these were thick but sometimes they were of normal consistence, the helminthological analysis showed a presence of the first larval stage of E. cervi and V. sagittatus; type 2 - brown-black nodes clearly differentiated from the surrounding tissue, the helminthological examination of these areas showed a presence of adult forms and first larval stage of $V$. sagittatus and first larval stage of $E$. cervi; type 3 - small, hard nodules of a diameter from 1 to $5 \mathrm{~mm}$ under the serous surface of the lungs, no parasitic forms were established in them by helmintholarvoscopy after the Baermann technique, but upon compression of the tissue after boiling in lactic acid sometimes larval parts were visible.

Histologically, in the lesions of type 1 serous and desquamatous bronchitis, few parasite forms in the bronchi and haemorrhages in the alveoli and the alveolar septa were established. Abnormalities in the lesions of type 2 were especially numerous. The lung parenchyma was affected as well as the interstitium. Bronchi were often obstructed by parasites, desquamated epithelial cells, lymphocytes, alveolar macrophages, neutrophils and eosinophils, and were encircled by lymphoid hyperplasia (Plate I, Fig. 1a). Many alveoli contained a great number of different developmental forms of parasites (Fig. 1b). In some cases, the affected alveoli were situated peripherally to parasitize bronchi while in others such proximity was not recorded. A settling of adult worms in the acini in ripped alveolar septa and confluent alveoli was observed (Fig. 1c). Eggs and larvae of parasites in the alveoli were often surrounded with macrophages and giant cells, sometimes fused together and forming syncitia (Fig. 1d). Accumulation of eosinophilic leukocytes in the alveolar lumen was also found (Fig. 1e). The alveolar septa were often hyperaemic and thickened due to infiltration with monocytes. In some cases alveolar emphysema was found (Fig. 1f). The node-like accumulation of large epithelial-like cells with big nuclei and hydropic cytoplasm of a diameter of 33 to $74 \mu \mathrm{m}$ presented a permanent finding in the septa. Normally these were found in considerably thickened septa with a ring-like hypercellularity of mononuclear cells around them (Plate II, Fig. 2a). The interstitium was at some places infiltrated with giant cells, eosinophil leukocytes and elsewhere granulomas built up from epitheloid and giant cells of the Langhans type were found (Fig. 2 b,c,d). 
A constant finding in the altered areas of this type was the lymphoid hyperplasia. Beside closely around the bronchi (Figure 2e), it was observed also in the lung interstitium. In several cases, among the lymphocytes in the interstitium parasite forms were visible but were absent in the alveoli (Fig. 2f). In other areas the reactive lymphoid hyperplasia associated with the alveolar septa was situated closely to parasitized alveoli, sometimes even encompassing the tissues along the border of the infected lobule (Fig. 2g). In some cases the lymphoid hyperplasia totally displaced the parenchyma of entire lung lobules (Fig. $2 \mathrm{~h}$ ). The severity of pathological disorders was considerably lower in lesions of type 3 . The changes were expressed mainly with accumulation of the typical node-like formations of large epithelial-like cells with big nuclei and hydropic cytoplasm in the interstitium and a diffuse intralobular hyperplasia of lymphoid tissue.

\section{Discussion}

High prevalence of Elaphostrongylus genus in red deer is established in different parts of the world, the Altai Mountains, Far East, Hungary and Poland (Demiaszkiewicz 1987). Mixed infections in red deer with protostrongylids of the genera Elaphostrongylus and Varestrongylus are also common occurrence (Rehbein et al. 2002).

The helminthological and histological analysis of macroscopic lesions showed that they depend in the first place on the parasite species. Thus, infections with $E$. cervi were most often associated with macroscopic lesions of types 1 and 3 . The dark-red areas of type 1 corresponded to the haemmorhages established in histological studies and described in infections with this parasite by other researchers (Kutzer and Prosl 1975; Rezáč and Blažek 1991) whereas the gray diffuse thickenings most probably result from the tissue reactivity displayed against the sexual products of the worms at a later stage. Lesions of type 3 were not found in red deer by other authors. They were, however, similar to the granulomas described by Beresford-Jones (1967) in sheep parasitized with Muellerius capillaris; McFadyean 1894 (cited by Beresford-Jones 1967) uses the category pseudotubercules for their description. In infection with $V$. sagittatus, a predominating finding constituted lesions of type 2 observed also by Kutzer and Prosl (1975), Řezáč and Blažek (1991) and Rehbein et al. (2002). In contrast to the authors mentioned above, we recorded such lesions directly under the lung capsule as well. Besides, in our cases their colour was considerably darker varying from brown to black; in that respect our observations were closest to those of Rehbein et al. (2002).

It follows from the results of this study that pathological changes in the lungs of red deer infected with $V$. sagittatus and $E$. cervi are of a defined specificity and they are to a large extent repetitive in individual animals. As such, they are of a high diagnostic value. Studies on the subject should be extended as research is presently conducted on limited pathological material, while most of the assumptions require consistent experimental evidence.

\section{Acknowledgements}

This work was supported by the project "Initiatives for mobilizing stimulating and increasing of scientific investigations quality of young scientific potential in priority areas of medico-biological sciences" founded from European Social Fund and Republic of Bulgaria, "Development of human resources" 2007-2013 (№ BG051 PO001-3.03.04/46-28.08.2009). The authors thank the Executive Forest Agency of Bulgaria and F. Eng. Kovashki for co-operation in obtaining materials.

\section{References}

Beresford-Jones WP 1967: Observation on Muellerius capillaris (Muller, 1889) Cameron, 1927. III. Experimental infection of sheep. Res Vet Sci 8: 272-279

Bregoli M, Natale A, Cova M, Vascellari M, Pasolli C 2006: Meningealnematodiasis in a red deer (Cervus elaphus) in northeastern Italy. Vet Arh 76: 287-293 
Demiaszkiewicz AW 1987: Species composition and the extensiveness of invasion of deer by nematoda of the family Protostrongylidae at selected hunting grounds. Wiad Parazytol 33: 57-62

English A, Watt C, Corrigall W 1985: Larvae of Elaphostrongylus cervi in the deer of Scotland. Vet Rec 116: 254-256

Eriksen L, Monrad J, Steen M 1989: Elaphostrongylus cervi in Danish wild red deer (Cervus elaphus). Vet Rec 124: 124

Kutzer E, Prosl H 1975: Contribution to the knowledge of Elaphostrongylus cervi Cameron, 1931. I. Morphology and diagnosis. Wien Tierärztl Mschr 62: 258-266

Panayotova-Pencheva M, Alexandrov M 2010: Some pathological features of lungs from domestic and wild ruminants with single and mixed protostrongylid infections. Vet Med Int 2010, doi: 10.4061/2010/741062

Pusterla N, Hertzberg H, Viglezio M, Vanzetti T, Braun U 1998: Examinations on the incidence of lumbar paralysis in goats and the occurence of Elaphostrongylus cervi in red deer in the Canton Ticino. Schweizer Arch fur Tierheil 140: 76-82

Rehbein S, Lutz W, Visser M, Winter R 2002: Investigation of the parasite fauna of game animals of NorthrhineWestfalia. 3. Endoparasites of red deer. Zschr Jagdwiss 48: 69-93

Řezáč P, Blažek K 1991: Pathologic changes in the lungs of deer spontaneously infected with nematodes from the Protostrongylidae family. Vet Med (Praha) 36: 315-320

Sutherland RJ 1976: Elaphostrongylus cervi in cervids in New Zealand. 1. The cross and histological lesions in Red deer (Cervus elaphus). New Zeal Vet J 24: 263-266

Vicente J, Gortazar C 2001: High prevalence of large spiny-tailed protostrongylid larvae in Iberian red deer. Vet Parasitol 96: 165-170 
Plate I

Panayotova-Pencheva M. S. et al.: Etiopathological ... pp. 349-352

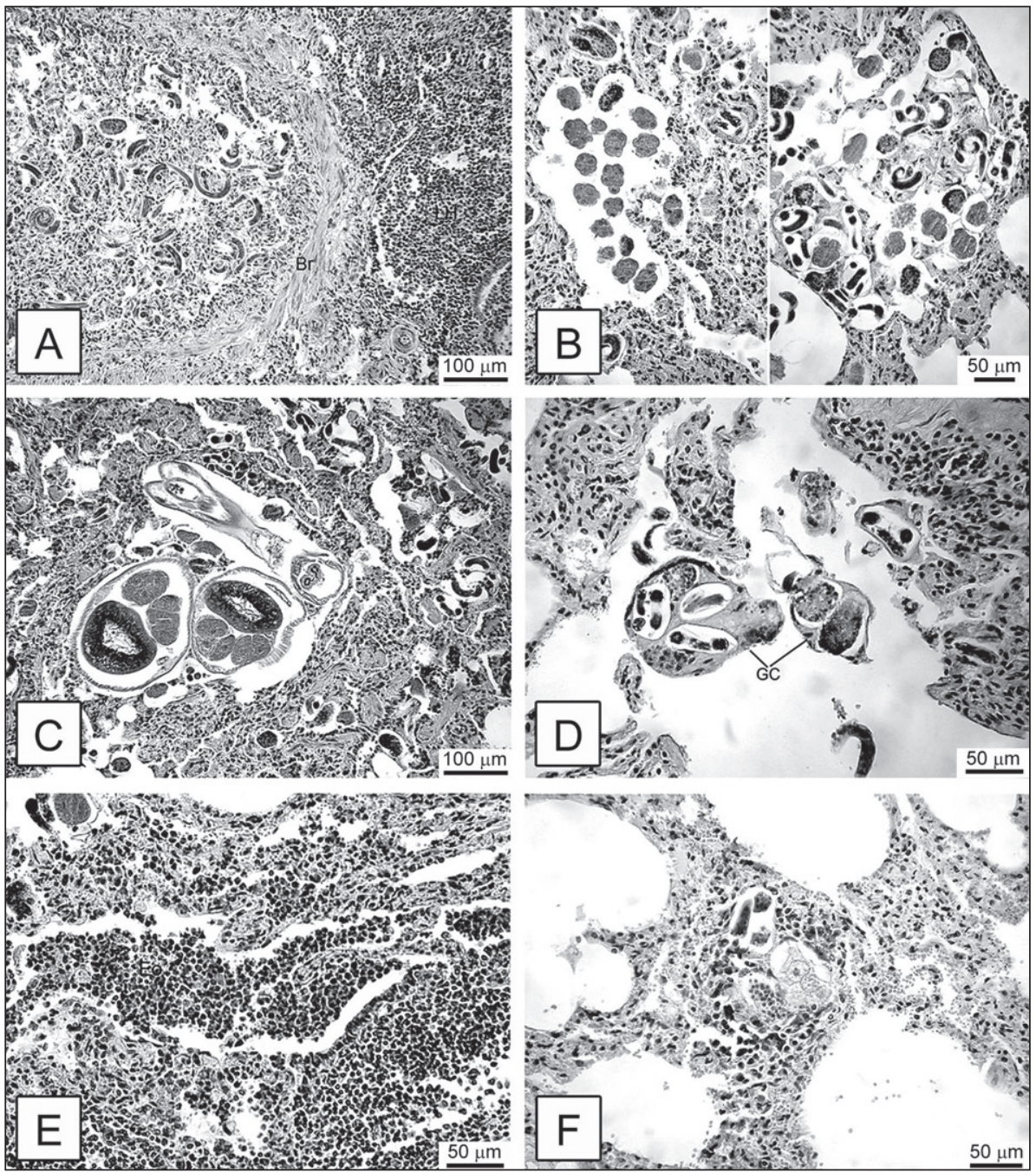

Fig. 1. Red deer lungs with Varestrongylus sagittatus and Elaphostrongylus cervi infections. Haematoxyline and eosin staining (HE).

A - bronchus $(\mathrm{Br})$ obstructed by parasites, desquamated epithelial cells, lymphocytes, alveolar macrophages, neutrophils and eosinophils; hyperplasia of lymphoid tissue around it, B - parasite eggs and larvae in the alveolar lumen, $\mathrm{C}$ - settling of adult $V$. sagittatus in acini in ripped alveolar septa and confluent alveoli, D syncitia of macrophages and giant cells (GC) around the eggs and larvae in the alveoli, E - an accumulation of eosinophilic leucocytes (Eo) in the alveolar lumen, F - an alveolar emphysema. 


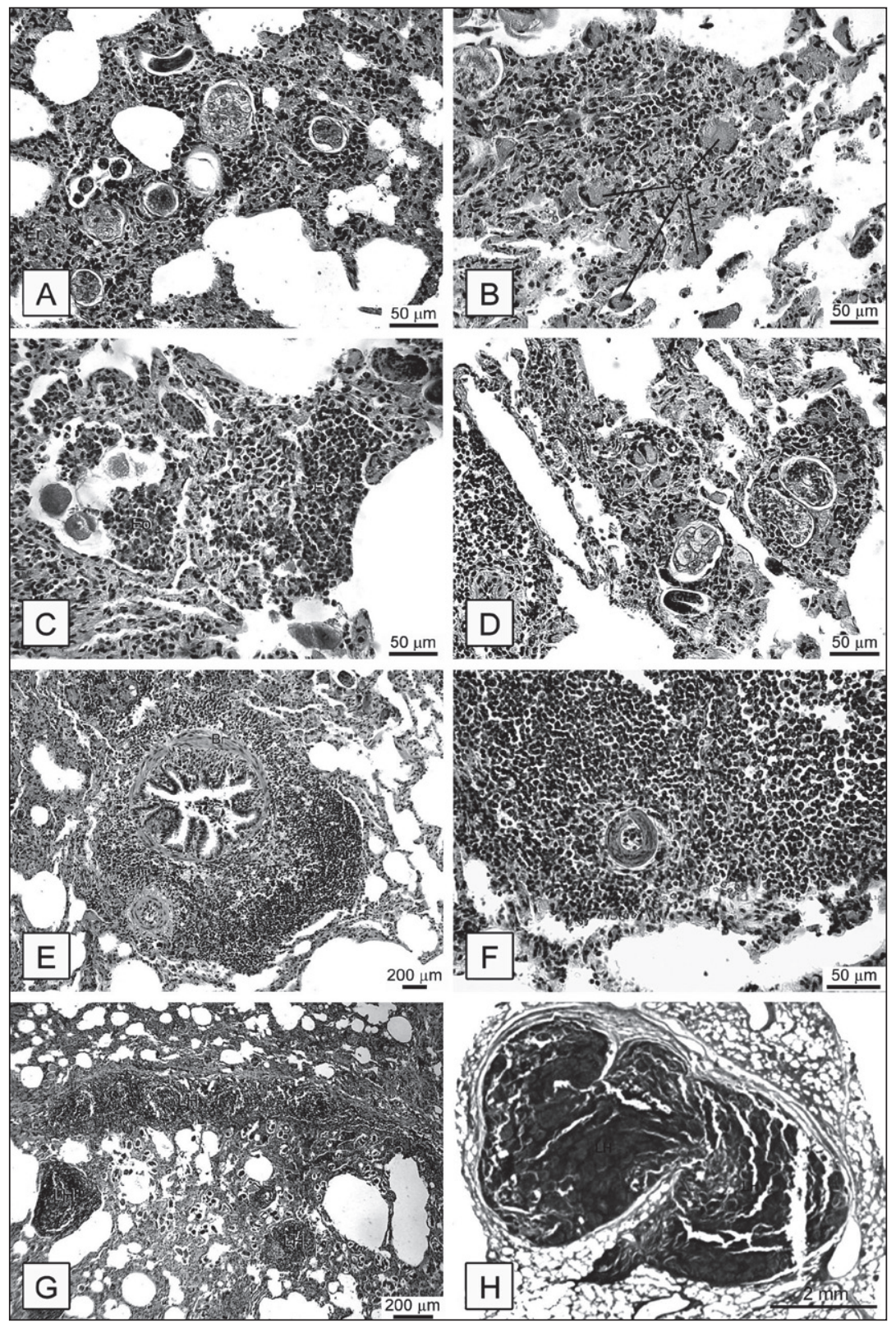

Fig. 2. Red deer lungs with Varestrongylus sagittatus and Elaphostrongylus cervi infections. Haematoxyline and eosin staining (HE).

A - thickened septa; node-like accumulation of large epithelial-like cells with big nuclei and hydropic cytoplasm, a ring-like hypercellularity of mononuclear cells around them; interstitium infiltrated with erythrocytes, B - interstitium infiltrated with giant cells (GC), C - interstitium infiltrated with eosinophil leucocytes (Eo), D - granuloma built up from epitheloid and giant cells of the Langhans type, E peribronchial lymphoid hyperplasia, F - disseminated lymphoid hyperplasia in the interstitium; parasite forms in the septa, no parasitized alveoli, G - disseminated lymphoid hyperplasia (LH) around parasitized alveoli; perilobular lymphoid hyperplasia, H - intralobular lymphoid hyperplasia. 